\title{
Influência das épocas de manejo químico da aveia-preta sobre a incidência de plantas daninhas e desempenho produtivo do milho
}

\section{Influence of black-oats chemical management periods on the incidence of weeds and productive performance of maize}

\author{
João Edson Kaefer ${ }^{*}$; Vandeir Francisco Guimarães²; Alfredo Richart1; \\ Rodrigo Campagnolo ${ }^{1}$; Telis Augusto Wendling ${ }^{3}$
}

\begin{abstract}
Resumo
A semeadura do milho em sucessão ao cultivo da aveia-preta é uma prática amplamente adotada no Sul do Brasil, especialmente em sistema de agricultura conservacionista. A época de manejo da aveia-preta em relação à semeadura do milho é um fator determinante, pois dela depende o tempo de permanência dos resíduos de aveia sobre o solo, podendo ainda interferir na produtividade da cultura sucessora. Neste sentido, o objetivo deste trabalho foi avaliar a influência da época de manejo químico da aveiapreta sobre os componentes da produção e a produtividade da cultura do milho. O experimento foi desenvolvido na unidade experimental da PUCPR - Campus Toledo, nos anos agrícolas 2008/2009 e 2009/2010, sob delineamento experimental de blocos ao acaso, com cinco tratamentos (semeadura do milho em 0, 7, 14, 21 e 28 dias após o manejo químico da aveia-preta) com quatro repetições. Para cada um dos tratamentos, aveia-preta foi semeada semanalmente, sendo posteriormente manejada no estádio de florescimento por meio químico com $48 \mathrm{~g} \mathrm{L-1}$ i. a. de glifosate, na dosagem de 2,0 L ha-1 do produto comercial, utilizando-se um volume de calda de $150 \mathrm{~L}$ ha-1, sendo as plantas deixadas intactas no momento da semeadura do milho. As variáveis avaliadas foram produtividade de massa seca da aveia-preta, incidência de plantas daninhas, percentual de plantas de milho emergidas, altura de inserção de espiga, diâmetro basal do colmo, comprimento e diâmetro de espiga, número de fileiras de grãos por espiga, massa de 1.000 grãos e produtividade. A incidência de plantas daninhas decresceu progressivamente com a diminuição do tempo entre o manejo da aveia-preta e a semeadura do milho em ambos os anos agrícolas. A época de manejo da aveia-preta não influenciou a maioria dos componentes da produção do milho, e consequentemente a produtividade de grãos.
\end{abstract}

Palavras-chave: Zea mays, plantas de cobertura, plantas daninhas, semeadura direta

\begin{abstract}
Maize sowing in succession to the cultivation of black oat is a practice widely adopted in southern Brazil, especially in no-tillage system. The time management of oats in relation to the sowing of corn is a determining factor, because it depends on the residence time of oat straw on the ground and may even interfere with the productivity of successor culture. In this sense, the objective was to evaluate the influence of time of chemical management of black oat on yield components of maize. The experiment was conducted at the experimental unit PUCPR - Campus Toledo, in the 2008/2009 and 2009/2010 agricultural years. The experimental design was randomized blocks with five treatments (maize sowing at $0,7,14,21$ and 28 days after chemical management of black oat) with four replications. For each
\end{abstract}

1 Professores da Pontifícia Universidade Católica do Paraná - Campus Toledo. E-mail: edson.kaefer@pucpr.br

2 Professor da Universidade Estadual do Oeste do Paraná - Campus Marechal Cândido Rondon. E-mail: vandeirfg@yahoo.com.br

3 Discente da Pontifícia Universidade Católica do Paraná - Campus Toledo. E-mail: celtanaram@yahoo.com.br

Autor para correspondência 
treatment, black-oats was sown weekly, and later in the flowering stage managed chemically with 48 $\mathrm{g} \mathrm{L}^{-1}$ a.i. of glyphosate at a dosage of $2.0 \mathrm{~L} \mathrm{ha}^{-1}$ of the commercial product, using a spray volume of $150 \mathrm{~L} \mathrm{ha}^{-1}$, the plants were left intact at the maize sowing period. The variables evaluated were black oat dry matter production, weed incidence, percentage of emerged plants, height of ear insertion, stem diameter, ear length and diameter, number of rows of kernels per ear, weight of 1000 and grain yield. The incidence of weeds decreased gradually decreasing the time between the management of black oat and maize sowing in both agriculture years. The time management of black oat did not affect most yield components of maize, especially productivity.

Key words: Zea mays, cover crops, weeds, no-tillage

\section{Introdução}

Um fator determinante no sucesso da produção de milho em semeadura direta é a escolha de espécies de cobertura do solo e a melhor época de semeadura destas em antecessão. Para tanto, dispõese de várias espécies com características adequadas, proporcionando incrementos na produtividade do milho cultivado em sucessão. Para beneficiar este sistema, as espécies de cobertura devem proteger o solo, melhorando também suas características físicas e químicas tais como densidade, porosidade, teor de matéria orgânica e fertilidade (AITA, 1997).

Pesquisas têm demonstrado os aspectos benéficos e as restrições do cultivo do milho sobre resíduos de aveia (AMADO; MIELNICZUK; AITA, 2002; MUZILLI, 2006). Apesar da aveiapreta não apresentar capacidade de fixar nitrogênio atmosférico, o interesse por esta espécie é atribuído à sua rusticidade em termos de doenças, ao rápido crescimento inicial, o qual favorece a cobertura do solo, à facilidade de produção de sementes, à semeadura e ao menor custo de produção, em comparação às leguminosas (CERETTA et al., 2002). Por outro lado, no cultivo do milho em sucessão a aveia-preta pode ocorrer a deficiência temporária de $\mathrm{N}$ no início do desenvolvimento da cultura, em função da alta relação $\mathrm{C} / \mathrm{N}$ da palha da aveia (imobilização do N), resultando também em redução na produtividade (AMADO et al., 1999; AITA et al., 2001; ARGENTA et al., 2001; AITA; GIACOMINI, 2003).

Entretanto, um fator benéfico da presença de restos culturais de aveia sobre a superfície do solo é o efeito que a palha proporciona sobre as características físicas e químicas do solo e também, no controle de plantas daninhas, o qual depende diretamente da quantidade de palha presente e do tempo de permanência dos resíduos sobre a superfície do solo (ARGENTA et al., 2001). No sistema de agricultura conservacionista, Kluthcouski et al. (2004) relatou maior concentração de sementes de plantas daninhas próximo à superfície do solo. Assim, com uma boa cobertura de solo, a agricultura conservacionista tende a acelerar o decréscimo no banco de sementes no solo por falta de indução à germinação e/ou pela perda da viabilidade.

Por outro lado, Oliveira et al. (2001) verificaram que o número total de plantas daninhas foi reduzido significativamente por diferentes níveis de palha de milho independentemente da presença de herbicida e da época de avaliação. Jakelaitis et al. (2010) verificaram que o efeito da cobertura morta de sorgo, milho, feijão-de-porco, girassol, estilosantes, arroz, soja e plantas daninhas não influenciou a produtividade do feijoeiro semeado após a dessecação química das espécies. Duarte Junior, Coelho e Freitas (2009) por sua vez, verificaram que em sistema agricultura conservacionista de cana-deaçúcar sobre o feijão-de-porco, houve menor índice de plantas daninhas em relação à cana cultivada convencionalmente, promovendo uma redução de $27 \%$ da produtividade de colmos. Portanto, o objetivo deste trabalho foi avaliar a influência da época de manejo químico da aveia-preta sobre os componentes da produção e produtividade da cultura do milho. 


\section{Material e Métodos}

O experimento foi conduzido nos anos agrícolas 2008/2009 e 2009/2010 no período de primavera/ verão na unidade experimental do curso de Agronomia da Pontifícia Universidade Católica do Paraná, campus Toledo, região Oeste do Paraná, localizada a $24^{\circ} 42^{\prime} 49^{\prime}$ ' S, e 53 44' $35^{\prime \prime} \mathrm{W}$ e altitude de $574 \mathrm{~m}$. Com base na classificação climática de Köeppen, o clima da região é do tipo subtropical úmido mesotérmico, com verões quentes, sem estações secas e com poucas geadas. A média de temperatura do mês mais quente é superior a $22^{\circ} \mathrm{C}$ e a do mês mais frio é inferior a $18^{\circ} \mathrm{C}$ (CAVIGLIONE et al., 2000). As médias mensais de temperatura e a precipitação do período de condução dos experimentos estão apresentadas na Figura 1. O solo foi classificado como Latossolo Vermelho Distroférrico típico (EMBRAPA, 2006).

Figura 1. Médias mensais de precipitação e temperatura da área do experimento nos anos 2008, 2009 e 2010.

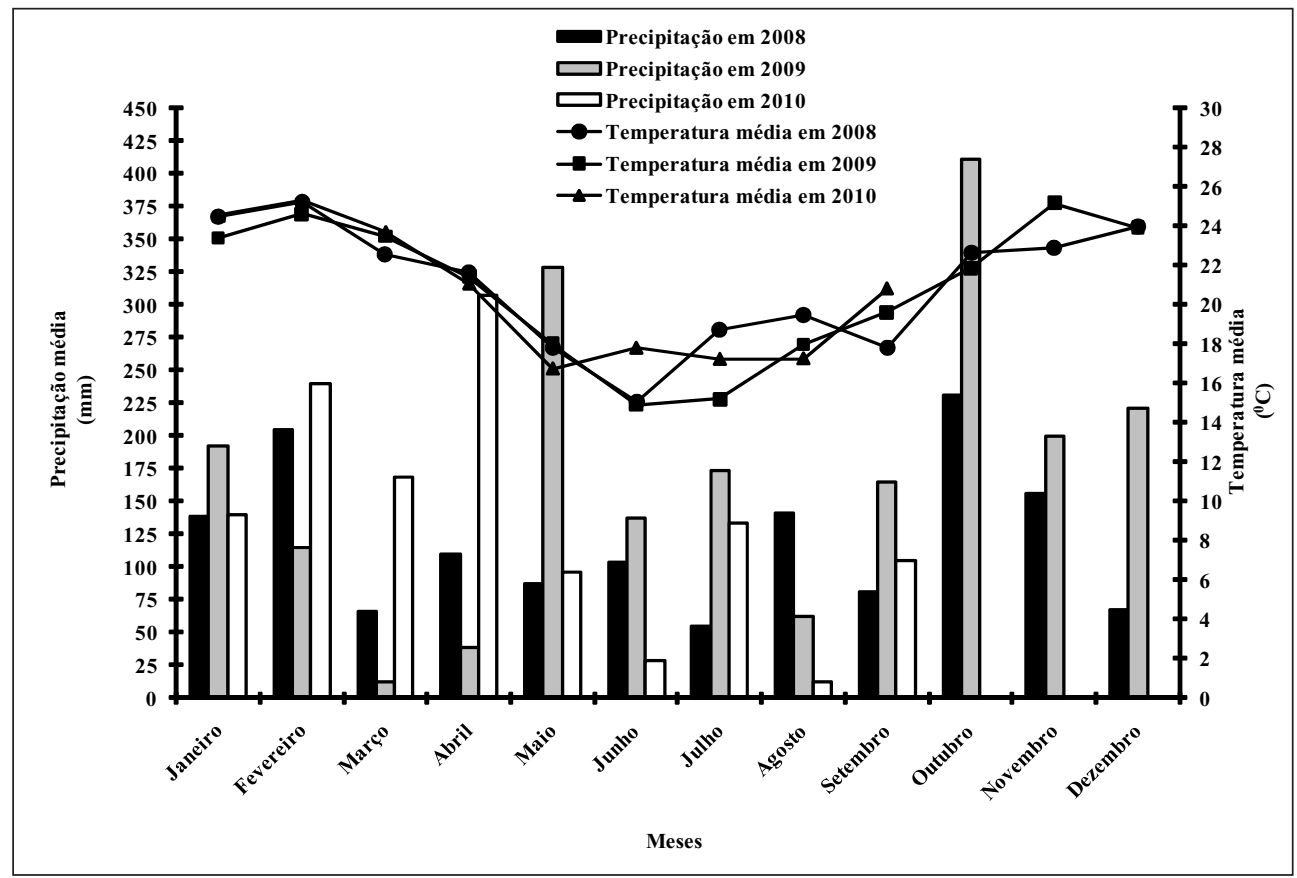

Fonte: SIMEPAR.

Antecedendo a instalação do experimento coletou-se amostras para determinar as características químicas (MIYAZAWA; PAVAN; $\mathrm{BLOCH}, 1992$ ) na profundidade de $0,0-0,2 \mathrm{~m}$, as quais apresentaram, $\mathrm{pH}$ em $\mathrm{CaCl}_{2} 5,6 ; 45,5 \mathrm{~g} \mathrm{dm}^{-3}$ de $\mathrm{MO} ; 31,9 \mathrm{mg} \mathrm{dm}^{-3}$ de $\mathrm{P} ; 3,97$ de $\mathrm{H}+\mathrm{Al} ; 5,52$ $\mathrm{cmol}_{\mathrm{c}} \mathrm{dm}^{-3}$ de $\mathrm{Ca}^{2+} ; 1,73 \mathrm{cmol}_{\mathrm{c}} \mathrm{dm}^{-3} \mathrm{Mg}^{2+} ; 0,28$ $\mathrm{cmol}_{\mathrm{c}} \mathrm{dm}^{-3}$ de $\mathrm{K}^{+}$. A composição granulométrica do solo (EMBRAPA, 1997) foi de 750, 140 e $110 \mathrm{~g} \mathrm{~kg}^{-1}$ de argila, silte e areia, respectivamente.

O delineamento experimental utilizado foi $\mathrm{o}$ de blocos ao acaso, com cinco tratamentos $(0,7$,
14, 21 e 28 dias após o manejo da aveia-preta) e quatro repetições. Os tratamentos compreenderam os dias transcorridos entre o manejo químico da aveia-preta e a semeadura do milho. Para compor cada um dos tratamentos, a aveia-preta cv. IAPAR - 61 foi semeada semanalmente, compreendendo as seguintes datas de semeadura: 6/03, 13/03, 20/03, 27/03 e 03/04 no ano agrícola de 2008 e, 05/03, 12/03, 19/03, 26/03 e 02/04 no ano agrícola de 2009. O espaçamento utilizado na entre linha foi de 0,17 m. No momento da semeadura da aveiapreta foram usados $150 \mathrm{~kg} \mathrm{ha}^{-1}$ da fórmula 12-15- 
15 de N- $\mathrm{P}_{2} \mathrm{O}_{5}-\mathrm{K}_{2} \mathrm{O}$, respectivamente. A aveia-preta foi manejada no estádio de florescimento por meio de controle químico com $48 \mathrm{~g} \mathrm{~L}^{-1}$ i. a. de glifosate, na dosagem de 2,0 $\mathrm{L} \mathrm{ha}^{-1}$ do produto comercial, utilizando-se um volume de calda de $150 \mathrm{~L} \mathrm{ha}^{-1}$, sendo as plantas deixadas intactas no momento da semeadura do milho. Na primeira semana, 07/08 e 06/08, respectivamente, no ano de 2008 e 2009 , realizou-se o manejo dos tratamentos 28 dias antes da semeadura do milho (DAS). Na semana seguinte, 14/08 e 13/08, respectivamente, no ano de 2008 e 2009, foi manejado o tratamento de 21 DAS. Nos dias 21/08 e 20/08, respectivamente no ano de 2008 e 2009, foi manejado o tratamento de 14 DAS. Nos dias 28/08 e 27/08, respectivamente no ano de 2008 e 2009, foi manejado o tratamento de 7 DAS. E nos dias 4/09 e 3/09, respectivamente no ano de 2008 e 2009 , foi manejado o tratamento zero DAS, quando logo após o manejo, foi semeado o milho em todas as parcelas do experimento.

O milho foi semeado em 04/09 e 03/09, respectivamente no ano de 2008 e 2009, com o uso de uma semeadoura dotada de sulcadores, A cultivar usada foi o híbrido simples DKB 330. Cada parcela foi composta por 3,0 $\mathrm{m}$ de largura e 5,0 $\mathrm{m}$ de comprimento, totalizando cinco linhas por parcelas espaçadas entre si por $0,7 \mathrm{~m}$, semeando-se quatro sementes por metro. Como área útil da parcela foram usadas as três linhas centrais, desconsiderandose um metro em cada uma das extremidades, totalizando uma área útil de $6,3 \mathrm{~m}^{2}$. Na semeadura do milho foram utilizados $500 \mathrm{~kg} \mathrm{ha}^{-1}$ da fórmula 12-15-15 de $\mathrm{N}-\mathrm{P}_{2} \mathrm{O}_{5}-\mathrm{K}_{2} \mathrm{O}$, respectivamente, e no estádio V6 foram aplicados a lanço $70 \mathrm{~kg} \mathrm{ha}^{-1}$ de $\mathrm{N}$ na forma de sulfato de amônio (COELHO et al., 2006).

Antes da semeadura do milho foram coletados os resíduos da aveia-preta da área de $1,0 \mathrm{~m}^{2}$ de cada parcela para determinar a quantidade de massa seca remanescente. As amostras foram secas a $65 \pm 1^{\circ} \mathrm{C}$ até a estabilização da massa.
Para a avaliação das espécies de plantas daninhas nas parcelas, realizaram-se contagens semanalmente a partir da semeadura até o estádio R1 do milho, contando-se o número de plantas daninhas emergidas em uma área de $1,0 \mathrm{~m}^{2}$, a qual foi definida de forma aleatória dentro de cada parcela (ERASMO; PINHEIRO; COSTA, 2004). Para a contagem das plantas daninhas foi considerado o total de plantas das quatro espécies de maior incidência: picão preto (Bidens pilosa), caruru (Amaranthus sp), capim colchão (Digitaria horizontalis) e leiteiro (Euphorbia heterophylla).

Com relação à emergência da cultura do milho, realizou-se a contagem de plântulas emergidas a partir da data de semeadura do milho, as quais foram realizadas em quatro metros de cada parcela, estendendo-se até a data de estabilização da emergência, ou seja, quando não se observou mais novas emergências, o que ocorreu na data de 15/09 e 14/09, respectivamente, nos anos 2008 e 2009. Considerou-se como planta emergida, aquela que já havia emitido o hipocótilo.

As determinações de diâmetro basal do colmo e altura de inserção da espiga foram realizadas no estádio R6. As medições de diâmetro basal do colmo foram realizadas na altura do primeiro entrenó visível de dez plantas localizadas dentro da área útil $\left(6,3 \mathrm{~m}^{2}\right)$ considerando as três linhas centrais e desconsiderando $1,0 \mathrm{~m}$ em cada uma das suas extremidades. A altura de inserção de espiga foi realizada medindo-se a distância entre a base da planta até o nó de inserção da primeira espiga de dez plantas localizadas dentro da área útil.

Após atingir a maturação fisiológica $(17 \%$ de umidade), as espigas das plantas localizadas dentro da área útil foram colhidas e despalhadas para a determinação dos componentes da produção. O comprimento de espiga foi obtido medindo-se dez espigas desde a sua base até a ponta. $\mathrm{O}$ diâmetro de espiga foi obtido medindo-se o diâmetro de dez espigas em seu terço médio. O número de fileiras de 
grãos por espiga foi obtido contando-se o número de fileiras de grãos em cada uma de dez espigas colhidas da área útil. A massa de 1.000 grãos foi obtida após a debulha manual de todas as espigas da área útil, das quais retiraram-se dez subamostras de 100 grãos que foram pesadas em uma balança digital, sendo a umidade corrigida para $13 \%$. Para determinar a produtividade foi utilizada toda a massa de grãos das espigas da área útil da parcela, sendo a umidade corrigida para 13\%, extrapolandose os resultados por meio de cálculo para $\mathrm{kg} \mathrm{ha}^{-1}$.

Os dados obtidos em cada experimento foram submetidos às análises de variância isoladamente e as médias quando significativas foram comparadas pelo teste de Tukey a $5 \%$ de probabilidade. Para a realização das análises estatísticas utilizou-se o software SISVAR (FERREIRA, 2003).

\section{Resultados e Discussão}

Para a produtividade de massa seca da aveia (MSA), observa-se que no experimento I (2008) não ocorreram diferenças significativas $(p>0,05)$ em função da época do manejo químico em relação à semeadura da cultura do milho (Tabela 1). Entretanto, para o experimento II (2009), verificaram-se respostas significativas $(p<0,05)$ para a produção MSA para as épocas de manejo da aveia-preta em relação à semeadura da cultura do milho (Tabela 1). A maior produtividade de MSA observado no experimento II provavelmente ocorreu em função dos maiores índices pluviométricos observados em 2009 durante o desenvolvimento da cultura em comparação a 2008 (Figura 1). Em ambos experimentos, os maiores valores foram constatados quando o manejo químico foi próximo (7 DAS) ou simultâneo (0 DAS) a semeadura do milho.

Tabela 1. Resultados médios para produtividade de massa seca da aveia (MSA), incidência de plantas daninhas (IPD) e percentual de plantas de milho emergidas (PE) em função do manejo químico da aveia que antecedeu a semeadura do milho em dois cultivos (anos agrícolas de 2008/2009 e 2009/2010, respectivamente, experimentos I e II) em Latossolo Vermelho Eutroférrico típico, região de Toledo, oeste do Paraná.

\begin{tabular}{|c|c|c|c|c|c|c|}
\hline \multirow{2}{*}{$\begin{array}{l}\text { Manejo químico } \\
\text { (DAS) }\end{array}$} & \multicolumn{2}{|c|}{ MSA } & \multicolumn{2}{|c|}{ IPD } & \multicolumn{2}{|c|}{ PE } \\
\hline & I & II & I & II & I & II \\
\hline & \multicolumn{2}{|c|}{$\mathrm{kg} \mathrm{ha}^{-1} \longleftarrow$} & \multicolumn{2}{|c|}{ plantas $\mathrm{m}^{-2}$} & \multicolumn{2}{|c|}{$\%$} \\
\hline 0 & $1.865 \mathrm{a}^{1}$ & $2.220 \mathrm{a}$ & $17,5 \mathrm{c}$ & $39,0 \mathrm{~b}$ & $76 a$ & $87 \mathrm{a}$ \\
\hline 7 & $1.865 \mathrm{a}$ & $1.870 \mathrm{ab}$ & $20,0 \mathrm{ab}$ & $37,0 \mathrm{~b}$ & $80 \mathrm{a}$ & $94 \mathrm{a}$ \\
\hline 14 & $1.715 \mathrm{a}$ & $1.770 \mathrm{ab}$ & $33,0 \mathrm{abc}$ & $43,5 \mathrm{~b}$ & $92 \mathrm{a}$ & $90 \mathrm{a}$ \\
\hline 21 & $1.510 \mathrm{a}$ & $1.490 \mathrm{~b}$ & $39,5 \mathrm{ab}$ & $53,7 \mathrm{ab}$ & $84 \mathrm{a}$ & $91 \mathrm{a}$ \\
\hline 28 & $1.465 \mathrm{a}$ & $1.550 \mathrm{~b}$ & $48,2 \mathrm{a}$ & $70,7 \mathrm{a}$ & $80 \mathrm{a}$ & $92 \mathrm{a}$ \\
\hline Média & 1.680 & 178 & 31,65 & 48,8 & 82,40 & 91,10 \\
\hline C.V & 11,7 & 12,75 & 28,21 & 23,65 & 10,78 & 12,43 \\
\hline
\end{tabular}

${ }^{1}$ Médias seguidas da mesma letra minúscula na coluna, não diferem entre si pelo teste de Tukey à $5 \%$ de probabilidade.

Fonte: Elaboração dos autores.

Comparando-se os tratamentos do manejo realizado aos 28 com 0 DAS, observa-se que ocorreu uma redução de $21,5 \%$ e $30,2 \%$ da MSA, respectivamente, experimento I e II. Siqueira (1999) verificou que um fator importante que interfere na persistência da palha sobre o solo é a relação $\mathrm{C} / \mathrm{N}$. Entretanto, apesar de não ter sido determinada no presente trabalho, provavelmente a relação $\mathrm{C} / \mathrm{N}$ não foi o fator determinante para a variação nos níveis da MSA, uma vez que em todos os tratamentos a aveia foi manejada quimicamente no estádio de florescimento. O que provavelmente pode ter influenciado uma maior MSA próximo ao manejo químico (7 DAS) ou simultaneamente (0 DAS) a semeadura é que a semeadura tardia da aveia promoveu maior produção de MAS, provavelmente 
devido as condições climáticas mais ou menos favoráveis para o desenvolvimento da aveia, uma vez que as semeaduras ocorreram em épocas diferentes.

A incidência de plantas daninhas diminuiu significativamente com a redução do tempo entre o manejo da aveia e a semeadura do milho em ambos experimentos (Tabela 1). Isso demonstra que a quantidade de resíduos presentes sobre o solo tem influência direta sobre o nível de infestação de plantas daninhas (SANTOS, 2007). Resultados semelhantes foram obtidos por Oliveira et al. (2001) que observaram que a população total de plantas daninhas foi afetada significativamente pela quantidade de palhada, independentemente da presença de herbicidas e/ou da época de avaliação. A redução na incidência de plantas daninhas nos dois anos que o experimento foi conduzido pode ser atribuída ao efeito supressor da palha sobre a germinação de plantas daninhas, proporcionando uma menor incidência de luz solar, ocasionado uma menor superação da dormência de algumas espécies componentes do banco de sementes. Esse fato foi corroborado por Correia e Durigan (2004), que verificaram que além do efeito da luz, a presença de uma massa vegetal na superfície do solo reconhecidamente exerce efeito supressor na germinação das plantas daninhas.

Cobucci, Kluthcouski e Aidar(2001) constataram que na cultura do feijoeiro, a maior quantidade de cobertura morta de braquiária (Brachiaria brizantha), uma forrageira de verão muito usada em sistemas de integração de lavoura com pecuária, contribuiu para a menor emergência de plantas daninhas no cultivo de inverno, principalmente do leiteiro (Euphorbia heterofilla), caruru (Amaranthus hybridus) e capim-colchão (Digitaria horizontalis). Também Kluthcouski et al. (2004), notaram que a presença de palhada de braquiária (Brachiaria brizantha.) sobre o solo provoca interrupção no ciclo das plantas daninhas, diminuindo a sua incidência. De acordo com os mesmos autores, em ambientes com palha de braquiária reduziu-se em aproximadamente $70 \%$ a quantidade de herbicida necessária para o controle de plantas daninhas. Oliveira et al. (2001) avaliaram cinco níveis de palha de milho $\left(0,3,6,9\right.$ e $\left.12 \mathrm{Mg} \mathrm{ha}^{-1}\right)$ e observaram que para cada tonelada de palha adicionada obtiveram um controle de aproximadamente $4,0 \%$ no total das plantas daninhas.

A época de manejo da aveia-preta e consequentemente a quantidade de palha na superfície não influenciou o percentual de plantas de milho emergidas nos dois anos em que foi conduzido o experimento (Tabela 1). No entanto, deve-se tomar o cuidado com o manejo muito próximo à semeadura, pois isso pode acarretar uma concorrência inicial por água, assim como haver uma maior dificuldade de corte da palha, interferindo na distribuição e no contato da semente com o solo dificultando a emergência e o desenvolvimento inicial da cultura de interesse. Neste estudo, apesar de não ter ocorrido diferença significativa $(\mathrm{p}>0,05)$, observa-se que o percentual de plantas emergidas de milho foi ligeiramente inferior nos tratamentos onde a semeadura foi realizada próxima a data de manejo da aveia-preta quando comparada com os demais tratamentos. Resultados semelhantes foram obtidos por Santos (2007), que notou que a presença de plantas de cobertura de solo ainda verdes no momento da semeadura da soja limitaram inicialmente a disponibilidade de água, e posteriormente de nutrientes e luz para a cultura. Pereira et al. (2011) ao avaliarem tipos de manejo da palha de aveia-preta e do milheto na pré-semeadura da soja (sem manejo, roçada e dessecação com glifosato e com paraquat) e diferentes épocas de deposição da palha (zero, 15, 30 e 60 dias antes da semeadura da soja) constataram que o efeito da palha de aveia-preta e do milheto sobre o percentual de plantas de soja emergidas foi mais acentuado quando ocorreu até 15 dias antes da semeadura da cultura, sendo o efeito supressor da palha de aveia superior ao do milheto, independente do tipo de manejo.

Quanto aos componentes da produção do milho, constatou-se diferenças significativas $(\mathrm{p}<0,05)$ para 
o diâmetro de colmo (DC), comprimento de espiga (CE) e massa de 1.000 grãos (MMG) no primeiro experimento (ano agrícola 2008/2009), sendo que os demais componentes deste experimento não foram influenciados pelas épocas do manejo químico da aveia-preta (Tabela 2). No segundo experimento (ano agrícola 2009/2010) não foram verificadas diferenças significativas $(p>0,05)$ para os componentes da produção e produtividade do milho em função das épocas de manejo químico da aveiapreta (Tabela 2). Um fator que pode ter contribuído para estes resultados foi à precipitação pluvial. Na safra de 2008/2009, a precipitação média foi de 140 $\mathrm{mm}$, enquanto que na safra 2009/2010, a média foi bem superior, chegando a $230 \mathrm{~mm}$, conforme pode ser observado na Figura 1.

Com relação à altura de inserção da espiga os valores variaram entre $0,9-1,06$ e $0,98-1,80 \mathrm{~m}$, respectivamente para o primeiro e segundo experimentos, sendo que a época do manejo químico da aveia-preta em relação à semeadura do milho não influenciou este componente. Já com relação ao diâmetro de colmo (DC) das plantas de milho, observa-se que os valores variaram de 0,023 $-0,025$ e $0,020,-0,022 \mathrm{~m}$, respectivamente, para o primeiro e o segundo experimentos. Estes resultados indicam que quanto mais próximo da semeadura for realizado o manejo químico da aveia-preta, maior será o DC.

Observam-se resultados bem distintos entre os dois períodos avaliados para o comprimento de espiga (CE), sendo que os maiores valores foram obtidos no primeiro experimento, provavelmente como efeito compensatório em função da menor população de plantas, variando de $0,16-0,18 \mathrm{~m}$, enquanto que no segundo experimento, os valores variaram entre $0,162-0,166 \mathrm{~m}$.
Quanto ao diâmetro de espiga (DE) e número de fileiras por espiga (NFE), observa-se que a época do manejo químico da aveia-preta em ralação à semeadura do milho não influenciou estes componentes. Estes resultados levam a inferir que, considerando a relevância do tempo de permanência da palhada ao longo do cultivo no sistema de semeadura direta, quanto menor o intervalo entre o manejo da aveia e a semeadura da cultura de milho, mais eficiente poderá ser o sistema em função da manutenção da palha sobre o solo, resultando em menores perdas de água por evaporação.

Para a massa de mil grãos (MMG), os valores variam de 343 - 392 e 301 - 329 gramas, respectivamente, para o primeiro e segundo experimentos, provavelmente como efeito compensatório em função do menor número de plantas observadas no primeiro experimento. Fancelli e Dourado Neto (2000) verificaram que a massa de 1.000 grãos apresenta maior influência no aumento da produtividade. No entanto, os maiores valores foram obtidos no primeiro experimento, mas as maiores produtividades ocorreram no segundo experimento, provavelmente em função do maior número de plantas e pelas condições favoráveis de precipitação observados no segundo experimento (Figura 1). Na safra de 2008/2009 ocorreu estiagem bem no momento em que o milho estava na fase reprodutiva, repercutindo em redução substancial do potencial produtivo do híbrido. Por outro lado, na safra de 2009/2010, as condições climáticas foram favoráveis à cultura. Portanto, o manejo químico da aveia-preta próximo à semeadura do milho (7 DAS) ou simultaneamente (0 DAS) a semeadura foi onde se observou as melhores respostas para os componentes da produção do milho. 


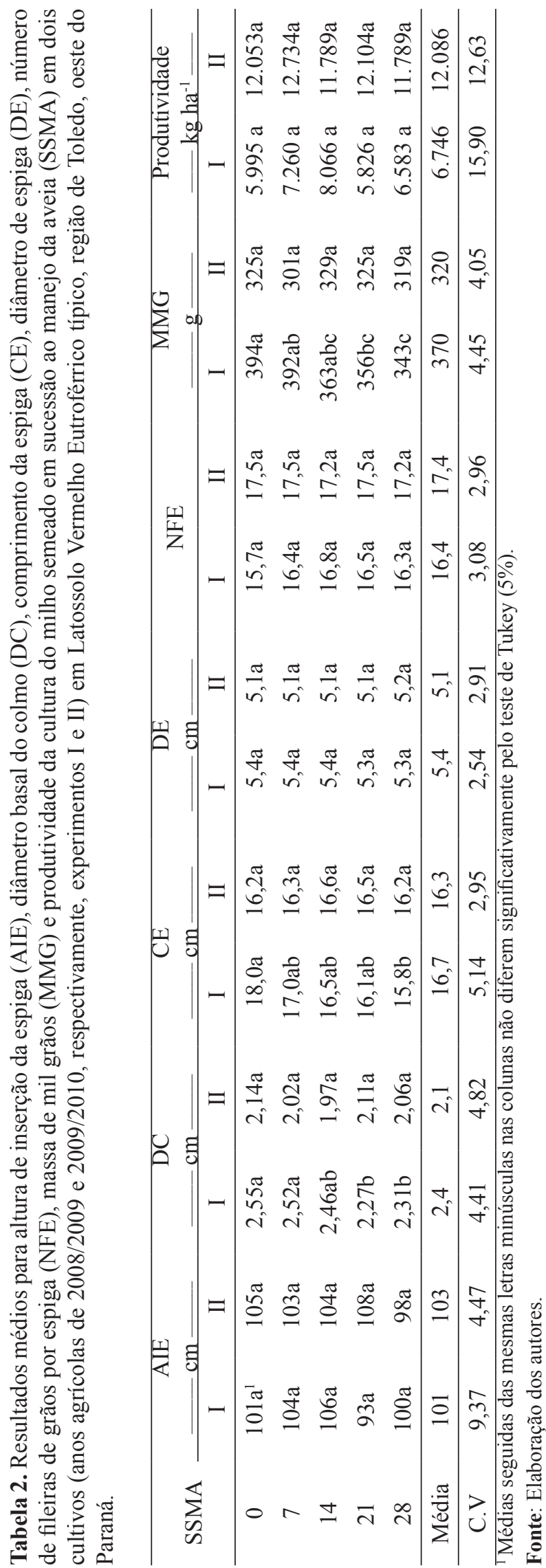

\section{Conclusões}

O Manejo da aveia-preta próximo à semeadura do milho (7 DAS) ou simultaneamente (0 DAS) a semeadura proporcionaram menores incidências de plantas daninhas.

Quanto mais próximo da semeadura for realizado o manejo químico da aveia-preta, maior será o diâmetro de colmo das plantas de milho.

A produtividade da cultura do milho não é influenciada pela época de manejo químico da aveia-preta.

\section{Referências}

AITA, C.; BASSO, C. J.; CERETTA, C. A.; GONÇALVES, C. N.; DA ROS, C. O. Plantas de cobertura de solo como fonte de nitrogênio ao milho. Revista Brasileira de Ciência do Solo, Viçosa, v. 25, n. 1, p. 157-165, 2001.

AITA, C.; GIACOMINI, S. J. Decomposição e liberação de nitrogênio de resíduos culturais de plantas de cobertura de solo solteiras e consorciadas. Revista Brasileira de Ciência do Solo, Viçosa, v. 27, n. 3, p. 601-612, 2003.

AITA, C. Dinâmica do nitrogênio no solo durante a decomposição de plantas de cobertura: efeito sobre a disponibilidade de nitrogênio para a cultura em sucessão. In: FRIES, M. R.; DALMOLIN, R .S. D. (Coord.). Atualização em recomendação de adubação e calagem: ênfase em plantio direto. Universidade Federal de Santa Maria: Pallotti, 1997. p. 76-111.

AMADO, T. J. C.; MIELNICZUK, J.; AITA, C. Recomendação de adubação nitrogenada para o milho no RS e SC adaptada ao uso de culturas de cobertura do solo, sob sistema plantio direto. Revista Brasileira de Ciência do Solo, Viçosa, v. 26, n. 1, p. 241-248, 2002.

AMADO, T. J. C.; MIELNICZUCK, J.; FERNANDES, S. B. V.; BAYER, C. Culturas de cobertura, acúmulo de nitrogênio total no solo e produtividade de milho. Revista Brasileira de Ciência do Solo, Viçosa, v. 23, n. 3, p. 679686, 1999.

ARGENTA, G.; SILVA, P. R. F. da; FLEKC, N. G.; BORTOLINI, C. G.; NEVES, R.; AGOSTINETTO, D. Efeitos do manejo mecânico e químico da aveia-preta no milho em sucessão e no controle do capim-papuã. Pesquisa Agropecuária Brasileira, Brasília, v. 36, n. 6, p. 851-860, jun. 2001. 
CAVIGLIONE, J. H.; CARAMORI, P. H.; KIIHL, L. B.; OLIVEIRA, D. Cartas climáticas do Paraná. Londrina: Iapar, 2000. 1 CD-ROM.

CERETTA, C. A.; BASSO, C. J.; FLECHA, A. M. T.; PAVINATO, P. S.; VIEIRA, F. C. B.; MAI, M. E. M. Manejo da adubação nitrogenada na sucessão aveia preta/milho, no sistema plantio direto. Revista Brasileira de Ciência do Solo, Viçosa, v. 26, n. 1, p. 163-171, 2002.

COBUCCI, T.; KLUTHCOUSKI, J.; AIDAR, H. Sistema Santa Fé: produção de forragem na entressafra. In: WORKSHOP INTERNACIONAL PROGRAMA DE INTEGRAÇÃO AGRICULTURA E PECUÁRIA PARA O DESENVOLVIMENTO SUSTENTÁVEL DAS SAVANAS TROPICAIS SULAMERICANAS, 123., 2001. Santo Antônio de Goiás, GO. Anais... Santo Antonio de Goiás, GO: Embrapa Arroz e Feijão, 2001. p. 125-135.

COELHO,A. M.; FRANÇA, A. E.; PITTA, G. V.; ALVES, V. M. C.; HERNANI, L. C. Sistemas de produção. 2. ed. Sete Lagoas: Embrapa Milho e Sorgo, 2006.

CORREIA, N. M.; DURIGAN, J. C. Emergência de plantas daninhas em solo coberto com palha de canade-açúcar. Planta Daninha, Viçosa, v. 22, n. 1, p. 11-17, 2004.

DUARTE JUNIOR, J. B.; COELHO, F. C.; FREITAS, S. P. Dinâmica de populações de plantas daninhas na canade-açúcar em sistema de plantio direto e convencional. Semina: Ciências Agrárias, Londrina, v. 30, n. 3, p. 595612, 2009.

EMPRESA BRASILEIRA DE PESQUISA AGROPECUÁRIA - EMBRAPA. Centro Nacional de Pesquisa de Solos. Sistema brasileiro de classificação de solos. 2. ed. Rio de Janeiro: Centro Nacional de Pesquisa Solos, 2006. 306 p.

Manual de métodos de análises de solo. 2. ed. rev. atual. Rio de Janeiro: Embrapa/Centro Nacional de Pesquisa de Solos, 1997. 212 p.

ERASMO, E. A. L.; PINHEIRO, L. L. A.; COSTA, N. V. Levantamento fitossociológico das comunidades de plantas infestantes em áreas de produção de arroz irrigado cultivado sob diferentes sistemas de manejo. Planta Daninha, Viçosa, v. 22, n. 2, p. 195-201, 2004.

FANCELLI, A. L.; DOURADO NETO, D. Produção de milho. Guaíba: Agropecuária, 2000. 360 p.

FERREIRA, D. F. Sisvar, versão 4.3. Lavras: Universidade Federal de Lavras, 2003. 1 CD-ROM.

KLUTHCOUSKI, J.; AIDAR, H.; STONE, L. F.; COBUCCI, T. Integração lavoura - pecuária e o manejo de plantas daninhas. Santo Antonio de Goiás, GO: Embrapa Arroz e Feijão, jun. 2004. (Informações Agronômicas, n. 106).

MIYAZAWA, M.; PAVAN, M. A.; BLOCH, M. F. M. Análise química de solo e tecido vegetal. Londrina: IAPAR, 1992. 17 p. (Circular, 74).

MUZILLI, O. Manejo do solo em sistema plantio direto. In: CASÃO JUNIOR, R.; SIQUEIRA, R.; MEHTA, Y. R; PASSINI, J. J. (Ed.). Sistema plantio direto com qualidade. Londrina: IAPAR; Foz do Iguaçu: Itaipu Binacional, 2006. p. 9-27.

OLIVEIRA, M. F.; ALVARENGA, R. C.; OLIVEIRA, A. C.; CRUZ, J. C. Efeito da palha e da mistura atrazine e metolachlor no controle de plantas daninhas na cultura do milho, em sistema de plantio direto. Pesquisa Agropecuária Brasileira, Brasília, v. 36, n. 1, p. 37-41. 2001.

PEREIRA, R. A.; ALVES, P. L. C. A.; CORRÊA, M. P.; DIAS, T. C. S. Influência da cobertura de aveiapreta e milheto sobre comunidade de plantas daninhas e produção de soja. Revista Brasileira de Ciências Agrárias. Pernambuco, v. 6, n. 1, p. 1-1, 2011.

SANTOS, J. F. Manejo da palhada de aveia-preta sobre o desenvolvimento e produção de soja em semeadura direta. Ponta Grossa: UEPG, 2007.

SIQUEIRA, R. Sistemas de preparo em diferentes tipos de coberturas vegetais do solo. 1999. Botucatu. Tese (Doutorado em Agronomia / Energia na Agricultura) - Faculdade de Ciências Agronômicas. Universidade Estadual Paulista, Botucatu. 
